\title{
Inappropriate prescribing of antithrombotic therapy in Ethiopian elderly population using updated 2015 STOPP/START criteria: a cross-sectional study
}

\section{Henok Getachew \\ Akshaya Srikanth \\ Bhagavathula \\ Tamrat Befekadu Abebe \\ Sewunet Admasu Belachew}

Department of Clinical Pharmacy,

School of Pharmacy, College of

Medicine and Health Sciences,

University of Gondar, Gondar,

Ethiopia

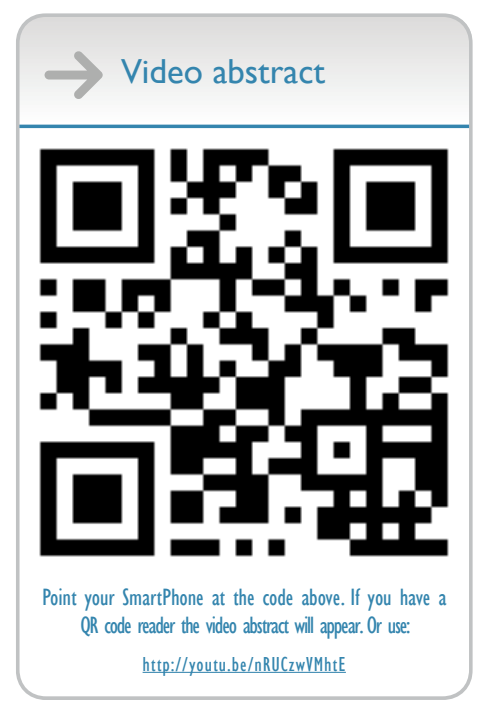

Correspondence: Henok Getachew Department of Clinical Pharmacy, School of Pharmacy, College of Medicine and Health Sciences, University of Gondar, PO Box 196, Gondar, Ethiopia

Tel +25 I $9 \mid 1438077$

Fax +25| 58 I| 4 |240

Email heniget@gmail.com
This article was published in the following Dove Press journal:

Clinical Interventions in Aging

20 June 2016

Number of times this article has been viewed

Background: Inappropriate use of antiplatelets and anticoagulants among elderly patients increases the risk of adverse outcomes. The aim of this study was to assess the prevalence of inappropriate prescribing of antithrombotic therapy in hospitalized elderly patients.

Methods: A retrospective cross-sectional, single-center study was conducted the Gondar University Hospital. A total of 156 hospitalized elderly patients fulfilling the inclusion/exclusion criteria were included in the study. The Screening Tool for Older Person's Prescription/Screening Tool to Alert doctors to Right Treatment criteria version 2 were applied to patients' data to identify the total number of inappropriate prescribing (IPs) including potentially inappropriate medications and potential prescribing omissions.

Results: A total of 70 IPs were identified in 156 patients who met the inclusion criteria. Of these, $36(51.4 \%)$ were identified as potentially inappropriate medications by the Screening Tool for Older Person's Prescription criteria. The prevalence of IP per patient indicated that 58 of the $156(37.2 \%)$ patients were exposed to at least one IP. Of these, $32(55.2 \%)$ had at least one potentially inappropriate medication and $33(56.9 \%)$ had at least one potential prescribing omission. Patients hospitalized due to venous thromboembolism (adjusted odds ratio [AOR] $=29.87$, 95\% confidence interval [CI], 1.26-708.6), stroke (AOR =7.74, 95\% CI, 1.27-47.29), or acute coronary syndrome (AOR $=13.48,95 \% \mathrm{CI}, 1.4-129.1$ ) were less likely to be exposed to an IP. An increase in Charlson comorbidity index score was associated with increased IP exposure (AOR $=0.60,95 \%$ CI, 0.39-0.945). IPs were about six times more likely to absent in patients prescribed with antiplatelet only therapy ( $\mathrm{AOR}=6.23,95 \% \mathrm{CI}, 1.90-20.37)$ than those receiving any other groups of antithrombotics.

Conclusion: IPs are less common in elderly patients primarily admitted due to venous thromboembolism, stroke, and acute coronary syndrome, and those elderly patients prescribed with only antiplatelet. Patients with higher Charlson comorbidity index were, however, associated with increased IPs exposure. Our study may guide further research to reduce high-risk prescription of antithrombotics in the elderly.

Keywords: prevalence, inappropriate prescribing, antithrombotic, STOPP/START criteria, elderly, Ethiopia

\section{Introduction}

Antithrombotics, including antiaggregants and anticoagulants, are complex drugs mainly used in primary and secondary cardiovascular disease prevention, and for treating thrombosis in patients with atrial fibrillation $(\mathrm{AF})$ or prosthetic heart valves. ${ }^{1,2}$ Different studies showed that the risk of bleeding and drug-related hospitalizations with antithrombotics contributes to the complexity of the treatment. ${ }^{3-5}$ For these reasons, 
health care practitioners need to pay special attention to the careful review of the medications for elderly patients along with concomitant pharmaceutical care. Physicians, nurses, pharmacists, nurse practitioners, physicians' assistants, and patients' families and caregivers are responsible for improving the care provided to elderly patients. ${ }^{6}$

A medication review is the structured evaluation of a patient's medication regimen aimed at optimizing drug therapy by minimizing the number of drug-related problems (DRPs). A DRP is defined as "an event or circumstance involving drug therapy that actually or potentially interferes with desired health outcomes". ${ }^{7}$ Several studies have shown the effectiveness of medication reviews conducted by health care practitioners at reducing the number of DRPs and the number of potentially inappropriate medicines (PIMs). ${ }^{8-12}$ Conducting medication reviews in the elderly population is especially important due to the high incidence of inappropriate drug prescribing, leading to higher rates of DRPs, hospitalizations, and adverse drug reactions. ${ }^{13-15}$

A number of specific criteria for identifying inappropriate prescribing (IP) in elderly patients have been developed, including the Beers criteria in 1991, updated in 1997 and 2003, ${ }^{16,17}$ the Canadian criteria, ${ }^{18}$ improved criteria in the elderly tool, ${ }^{19}$ Prescribing Appropriateness Index, ${ }^{20}$ Zhan's criteria, ${ }^{21}$ French Consensus Panel List, ${ }^{22}$ Australian Prescribing Indicators Tool, ${ }^{23}$ Norwegian General Practice criteria, ${ }^{24}$ Priscus List, ${ }^{25}$ the Thailand criteria, ${ }^{26}$ and the Rancourt criteria. ${ }^{27}$ The Screening Tool for Older Person's Prescription (STOPP) and Screening Tool to Alert doctors to Right Treatment (START) criteria were also created based on physiological systems. The STOPP/START comprises 65 evidence-based indicators in STOPP and 22 prescribing omission indicators in START. These validated criteria are widely applied internationally in different settings to detect PIMs and potential prescribing omissions (PPOs). ${ }^{11}$ In 2014, evidence was reassessed and a validated version 2 of STOPP/START criteria was developed comprising 80 STOPP and 34 START criteria. ${ }^{28}$ However, the clinical use of STOPP/START criteria version 2 in improving prescription appropriateness in older patients using antithrombotics has not yet been determined. In this study, STOPP/START criteria version 2 was preferred to other aforementioned criteria as it considers drug-drug and drug disease interaction, drug duplication, and PPO. ${ }^{29}$ Moreover, an updated version of STOPP/START criteria is needed due to the changing evidences. ${ }^{28}$ From STOPP/START criteria version 2, section A (indication of medication) and section $\mathrm{C}$ (antiplatelet/anticoagulant drugs) of STOPP criteria 2 and some criteria of section A (cardiovascular system) of START criteria 2 are relevant to antithrombotic therapy for this study.
There have been lots of changes made in STOPP/START version 2 , which are relevant to antithrombotic therapy. Some criteria have been removed from STOPP/START version 1, for example, the use of aspirin for primary prevention of cardiovascular disease in patients with diabetes (START criterion version 1), whereas some STOPP version 1 criteria were also removed from STOPP criteria 2 including aspirin with no history of coronary disease, cerebrovascular disease, or peripheral arterial occlusive symptoms; use of aspirin and warfarin in combination without histamine $\mathrm{H} 2$ receptor antagonist (except cimetidine because of interaction with warfarin) or proton pump inhibitor; dipyridamole as monotherapy for cardiovascular secondary prevention; and aspirin to treat dizziness not clearly attributable to cerebrovascular disease. ${ }^{11,28}$ However, some important criteria were missed in version 1 and included in STOPP criteria version 2, such as any drug prescribed without an evidence-based clinical indication; any drug prescribed beyond the recommended duration where treatment duration is well defined; long-term aspirin at doses $>160 \mathrm{mg} /$ day; aspirin plus clopidogrel as secondary stroke prevention, unless the patient has a coronary stent(s) inserted in the previous 12 months or concurrent acute coronary syndrome or has a high-grade symptomatic carotid arterial stenosis; antiplatelet agents with vitamin $\mathrm{K}$ antagonist, direct thrombin inhibitor (TI), or factor Xa inhibitors in patients with stable coronary disease, cerebrovascular disease, or peripheral arterial disease; aspirin in combination with vitamin $\mathrm{K}$ antagonist, direct TI, or factor Xa inhibitors in patients with chronic AF. ${ }^{28}$ No new criteria were added in START version 2 regarding antithrombotic therapy. The new version has more focused and specific criteria on antithrombotic therapy than STOPP/START version 1, which may lead to identifying higher prevalence of PIMs.

There are no published reports that assess the prevalence of IP of antithrombotic therapies in Ethiopia. Therefore, we conducted a retrospective study to estimate the prevalence of IP by screening hospitalized elderly patients needing antithrombotics using STOPP/START criteria version 2 . We also aimed at assessing the associated factors contributing to the potential IP in the Ethiopian elderly population.

\section{Materials and methods}

\section{Study design, setting, and participants}

This study was approved by the Institutional Review Board of the University of Gondar-School of Pharmacy, Gondar, Ethiopia. Confidentiality was maintained by using codes rather than patient names. Since the study is retrospective the Institutional Review Board of the University of GondarSchool of Pharmacy deemed patient consent unnecessary. 
This retrospective, single-center study was conducted at Gondar University Hospital (GUH) in Gondar city, Northwest Ethiopia. The GUH is a 550-bed teaching hospital serving a population of nearly 500,000 living in and around Gondar.

We reviewed the medical records (admissions between May 1, 2013 and April 30, 2015) of 156 hospitalized elderly patients aged $\geq 65$ years. Hospitalized patients presented various conditions, including congestive heart failure (CHF), venous thromboembolism (VTE), stroke (both ischemic and hemorrhagic), AF (both valvular and nonvalvular), acute coronary syndrome (ACS), peripheral vascular disease (PVD), patients with known comorbidity of cardiovascular diseases, history of coronary disease, cerebrovascular disease, or PVD, and/or those prescribed with antithrombotic medications. Patients with incomplete documented data (eg, absence of documented time when the medication was initiated or discontinued) were excluded. We considered patients' index admission as their first admission within our data collection period to meet the study inclusion criteria.

We collected patient demographics, documented previous medical history, relevant laboratory data, the primary reason for admission, comorbidities, number of medications prescribed, past history of peptic ulcer disease, history of recent bleeding, history of coronary disease, cerebrovascular disease, or PVD, type of antithrombotic therapy, and duration of hospital stay. International Classification of Diseases is the standard diagnostic tool for epidemiology, health management, and clinical purposes. ${ }^{30}$ International Classification of Diseases 9 was used for classifying of comorbidities in this study as it is being used in the medical system of our study area. A Charlson comorbidity index (CCI) was used as a measure of comorbidity. ${ }^{31}$

The STOPP/START criteria version $2^{28}$ was applied to patient data to identify the total number of instances of IP, including PIMs, PPOs, and the proportion of patients exposed to PIMs, PPOs, or both. Investigators reapplied the STOPP/START criteria to establish the accuracy of PIMs and PPOs identification.

\section{Statistical analysis}

Data were analyzed using the Statistical Package for Social Science Version 21 (IBM Corporation, Armonk, NY, USA). Continuous variables were presented as mean \pm standard deviation. Categorical variables were expressed as frequencies and percentages. Association between predictive variables (sociodemographic and clinical data of patients) and dependent variables (presence/absence of IP per patient) using binary logistic regression was done to identify determinants of IPs. Therefore, univariate logistic regression, which is used to analyze the association between an individual independent variable and outcome of interest, was tested to compute the crude odds ratio (COR), whereas multivariate logistic regression for analyzing two or more variables with outcome of interest was also tested to compute the adjusted odds ratio (AOR). Statistical significance was set at a two-sided $P$-value $<0.05$ in the multivariate analysis.

\section{Results}

Between May 2013 and April 2015, 156 patients were admitted with new-onset disease, meeting the inclusion criteria. The mean ( \pm standard deviation) age of the patients was 72.3 ( \pm 7.0 ) ranging from 65 to 98 years; $63.5 \%$ were female. The median CCI score was 2 (range $0-7$ ). Higher proportions of patients were primarily hospitalized due to stroke (37.8\%) and

Table I Characteristics and clinical data of the study population in Gondar University Hospital, Gondar, Ethiopia, between May I, 2013 and April 30, 2015

\begin{tabular}{|c|c|}
\hline Patient characteristics and clinical data & $\mathbf{N}(\%)$ \\
\hline Total number of study population, $\mathrm{N}$ & 156 \\
\hline Age in years, mean (SD) & $72.3( \pm 7.0)$ \\
\hline \multicolumn{2}{|l|}{ Sex, n (\%) } \\
\hline Male & $57(36.5)$ \\
\hline Female & $99(63.5)$ \\
\hline Hospital stay in days (median) & 13 (range I-55) \\
\hline \multicolumn{2}{|l|}{ Reason of admission, $\mathrm{n}(\%)$} \\
\hline $\mathrm{CHF}$ & $4 \mid(26.3)$ \\
\hline VTE & $9(5.8)$ \\
\hline Stroke & $59(37.8)$ \\
\hline $\mathrm{AF}$ & $15(9.6)$ \\
\hline ACS & $19(12.2)$ \\
\hline PVD & $2(1.3)$ \\
\hline Other & II (7.I) \\
\hline Number of medications prescribed, mean \pm SD & $4.92 \pm 1.86$ \\
\hline Charlson comorbidity index (median) & 2 (range $0-7$ ) \\
\hline \multicolumn{2}{|l|}{ Past history of peptic ulcer disease, $n(\%)$} \\
\hline Yes & $19(12.2)$ \\
\hline No & $37(87.8)$ \\
\hline \multicolumn{2}{|l|}{ History of recent bleeding, n (\%) } \\
\hline Yes & II (7) \\
\hline No & $145(93)$ \\
\hline \multicolumn{2}{|c|}{ History of coronary disease, cerebrovascular disease, or PVD, n (\%) } \\
\hline Yes & $63(40.4)$ \\
\hline No & $93(59.6)$ \\
\hline \multicolumn{2}{|l|}{ Types of antithrombotic therapy, n (\%) } \\
\hline No therapy & $16(10.2)$ \\
\hline Anticoagulant only & $34(21.8)$ \\
\hline Antiplatelet only & $68(43.6)$ \\
\hline Both & $38(24.4)$ \\
\hline
\end{tabular}

Notes: Others in "reason of admission" refers to hospitalization due to any medical condition other than listed cardiovascular disease, but have either a known comorbidity of cardiovascular disease or a history of coronary disease, cerebrovascular disease, or PVD; anticoagulants identified are warfarin, unfractionated heparin, and low-molecular-weight heparin (enoxaparin); antiplatelets prescribed are aspirin and clopidogrel.

Abbreviations: $\mathrm{ACS}$, acute coronary syndrome; $\mathrm{AF}$, atrial fibrillation; $\mathrm{CHF}$, congestive heart failure; PVD, peripheral vascular disease; VTE, venous thromboembolism; SD, standard deviation. 
Table 2 PIMs of antithrombotic therapy identified by the STOPP criteria version 2 at Gondar University Hospital, Gondar, Ethiopia, between May I, 2013 and April 30, 2015

\begin{tabular}{|c|c|}
\hline STOPP criteria version 2 & Number (\%) \\
\hline Any drug prescribed without an evidence-based clinical indication & $5(13.9)$ \\
\hline Any drug prescribed beyond the recommended duration, where treatment duration is well defined & $\mathrm{I}(2.8)$ \\
\hline Any duplicate drug class prescription & - \\
\hline Long-term aspirin at doses $>160 \mathrm{mg} /$ day & - \\
\hline Aspirin with a past history of peptic ulcer disease without concomitant PPI & $2(5.6)$ \\
\hline $\begin{array}{l}\text { Aspirin, clopidogrel, dipyridamole, vitamin } \mathrm{K} \text { antagonists, direct } \mathrm{Tls} \text {, or factor } \mathrm{Xa} \text { inhibitors with concurrent significant bleeding risk } \\
\text { (uncontrolled severe hypertension, bleeding diathesis, recent nontrivial spontaneous bleeding) }\end{array}$ & $7(19.4)$ \\
\hline $\begin{array}{l}\text { Aspirin plus clopidogrel as secondary stroke prevention, unless the patient has a coronary stent(s) inserted in the previous } \\
12 \text { months or concurrent acute coronary syndrome or has a high-grade symptomatic carotid arterial stenosis }\end{array}$ & - \\
\hline Aspirin in combination with vitamin $\mathrm{K}$ antagonist, direct $\mathrm{Tl}$, or factor $\mathrm{Xa}$ inhibitors in patients with chronic atrial fibrillation & $10(27.8)$ \\
\hline $\begin{array}{l}\text { Antiplatelet agents with vitamin } \mathrm{K} \text { antagonist, direct } \mathrm{TI} \text {, or factor } \mathrm{Xa} \text { inhibitors in patients with stable coronary disease, } \\
\text { cerebrovascular disease, or PAD }\end{array}$ & $6(16.7)$ \\
\hline Ticlopidine in any circumstances & - \\
\hline $\begin{array}{l}\text { Vitamin } \mathrm{K} \text { antagonist, direct } \mathrm{Tl} \text {, or factor } \mathrm{Xa} \text { inhibitors for first deep venous thrombosis without continuing provoking risk factors } \\
\text { (eg, thrombophilia) for }>6 \text { months }\end{array}$ & I (2.8) \\
\hline $\begin{array}{l}\text { Vitamin } \mathrm{K} \text { antagonist, direct Tl, or factor } \mathrm{Xa} \text { inhibitors for first pulmonary embolus without continuing provoking risk factors } \\
\text { for }>12 \text { months }\end{array}$ & - \\
\hline NSAID and vitamin $\mathrm{K}$ antagonist, direct $\mathrm{Tl}$, or factor $\mathrm{Xa}$ inhibitors in combination & I (2.8) \\
\hline NSAID with concurrent antiplatelet agent(s) without PPI prophylaxis & $3(8.3)$ \\
\hline Total number of antithrombotic-related PIMs & 36 \\
\hline
\end{tabular}

Notes: This table consists of antithrombotic-specific STOPP criteria extracted from STOPP/START criteria version 2. “-” indicates no PIMs observed.

Abbreviations: NSAID, nonsteroidal anti-inflammatory drugs; PAD, peripheral arterial disease; PIMs, potentially inappropriate medicines; PPI, proton pump inhibitor; START, Screening Tool to Alert doctors to Right Treatment; STOPP, Screening Tool for Older Person's Prescription; TI, thrombin inhibitor.

CHF (26.3\%), with a documented history of coronary disease, cerebrovascular disease, or PVD observed in 63 (40.4\%) patients. An antiplatelet alone (43.6\% patients) was the most commonly prescribed antithrombotic therapy (Table 1).

A total number of 70 IPs were identified in 156 patients regarding antithrombotic agents using STOPP/START criteria version 2. Thirty-six (51.4\%) PIMs were identified by the STOPP criteria. The prescription of aspirin in combination with a vitamin $\mathrm{K}$ antagonist, direct TI, or factor $\mathrm{Xa}$ inhibitors in patients with chronic AF showed frequent occurrence of PIM (27.8\%). The commission of aspirin, clopidogrel, dipyridamole, vitamin $\mathrm{K}$ antagonists, direct TIs, or factor Xa inhibitors (19.4\%) in patients with concurrent significant bleeding risk was observed (Table 2).
A total number of 34 (48.6\%) PPOs were identified by the START criteria. The most common observation was the omission of aspirin 19 (55.9\% of PPOs) in patients with a documented history of coronary disease, cerebrovascular disease, or PVD. The omission of vitamin K antagonists or direct TIs or factor Xa inhibitors $(41.2 \%)$ in the presence of chronic AF was also commonly identified (Table 3). Fifty-eight (58) of 156 (37.2\%) patients were exposed to at least one IP. Of these, seven (12.1\%) patients experienced both PIM and PPO, whereas 25 (43.1\%) patients and 26 (44.8\%) patients were exposed to PIM only and PPO only, respectively.

An assessment of the antithrombotic type indicated that a greater proportion of IP per patient was observed when no

Table 3 PPOs of antithrombotic therapy identified by the START criteria version 2 at Gondar University Hospital, Gondar, Ethiopia, between May I, 2013 and April 30, 2015

\begin{tabular}{l}
\hline START criteria version 2 \\
\hline Vitamin $\mathrm{K}$ antagonists, direct Tls, or factor Xa inhibitors in the presence of chronic AF \\
Aspirin (75 mg-I60 mg once daily) in the presence of chronic AF, where vitamin $\mathrm{K}$ antagonists, direct Tls, or factor Xa inhibitors \\
are contraindicated \\
Antiplatelet therapy (aspirin, clopidogrel, prasugrel, or ticagrelor) with a documented history of coronary disease, cerebrovascular \\
disease, or PVD \\
Total number of antithrombotic-related PPOs (55.9)
\end{tabular}

Note: This table consists of antithrombotic-specific START criteria extracted from STOPP/START criteria version 2.

Abbreviations: AF, atrial fibrillation; PPO, potential prescribing omissions; PVD, peripheral vascular disease; START, Screening Tool to Alert doctors to Right Treatment; STOPP, Screening Tool for Older Person's Prescription; TI, thrombin inhibitor. 


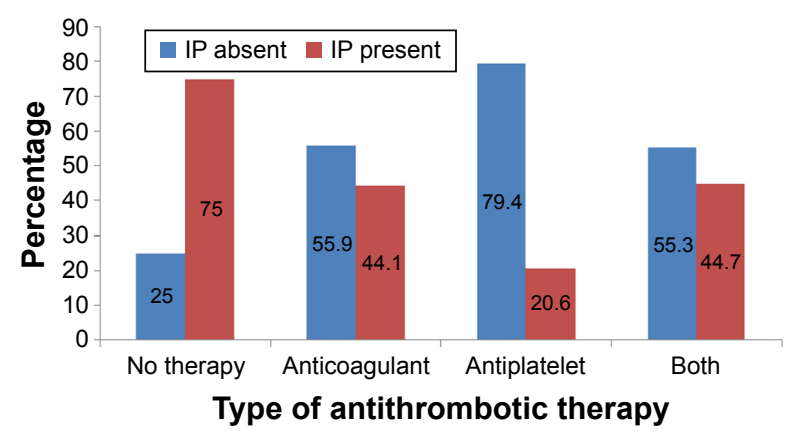

Figure I Proportion of IP exposure across different types of antithrombotic therapy per patient at Gondar University Hospital, Gondar, Ethiopia, between May I, 2013 and April 30, 2015.

Notes: In this study, anticoagulants identified are warfarin, unfractionated heparin, and low-molecular-weight heparin (enoxaparin); antiplatelets prescribed are aspirin and clopidogrel.

Abbreviation: IP, inappropriate prescribing.

antithrombotic drugs 12/16 (75\%) were prescribed (Figure 1). Based on the primary reason of admission, ten of $15(66.7 \%)$ hospitalized patients due to the primary diagnosis of AF were found to have IP (Figure 2).

Upon univariate analysis, COR revealed that IPs were less likely to be absent in patients with a higher number of prescribed medications $(\mathrm{COR}=0.78,95 \%$ confidence interval [CI], 0.64-0.934). In addition, the types of antithrombotic drugs prescribed had a statistically significant positive association with the likelihood of absence of IP. IPs were more likely to be absent in patients receiving either an anticoagulant (COR $=11.57,95 \% \mathrm{CI}, 3.23-41.42$ ) or an antiplatelet $(\mathrm{COR}=3.71,95 \% \mathrm{CI}, 1.01-13.59)$ alone. There was no statistically significant association between $\mathrm{CCI}$ and IP $(\mathrm{COR}=0.76,95 \% \mathrm{CI}, 0.55-1.03)$ (Table 4).

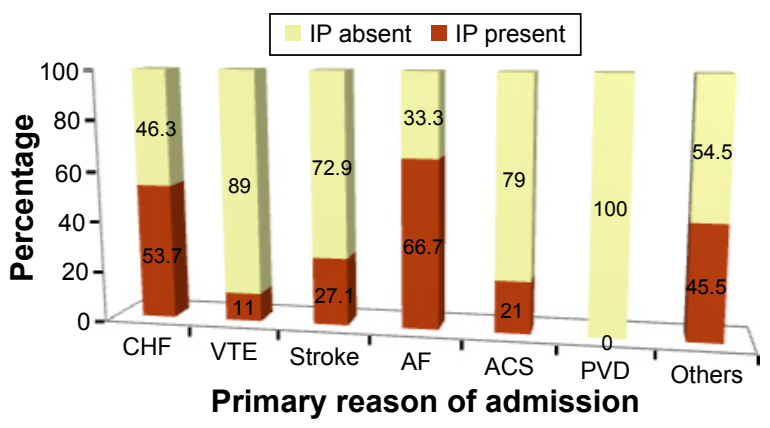

Figure 2 Prevalence of IP by the primary diagnosis of the patient at Gondar University Hospital, Gondar, Ethiopia, between May I, 2013 and April 30, 2015.

Notes: Others in "reason of admission" refer to hospitalization due to any medical condition other than listed cardiovascular disease, but have either a known comorbidity of cardiovascular disease or a history of coronary disease, cerebrovascular disease, or PVD.

Abbreviations: $\mathrm{ACS}$, acute coronary syndrome; $\mathrm{AF}$, atrial fibrillation; $\mathrm{CHF}$, congestive heart failure; IP, inappropriate prescribing; PVD, peripheral vascular disease; VTE, venous thromboembolism.
Multivariate analysis showed that patients hospitalized due to VTE $(A O R=29.87,95 \%$ CI, 1.26-708.6), stroke (AOR $=7.74,95 \% \mathrm{CI}, 1.27-47.29)$, or ACS (AOR =13.48, 95\% CI, 1.4-129.1) (Table 4) were more likely to have reduced IP exposure than patients admitted due to $\mathrm{CHF}$, AF, PVD, or other illnesses. An increase in the CCI score was associated with increased IP exposure $(\mathrm{AOR}=0.60$, 95\% CI, 0.39-0.945). IPs were about six times more likely to absent in patients prescribed with antiplatelet only therapy (AOR $=6.23,95 \% \mathrm{CI}, 1.90-20.37)$ than those receiving any other groups of antithrombotics. No other characteristics (age group, sex, number of medications prescribed, duration of hospital stay, past history of peptic ulcer disease, history of recent bleeding, history of coronary disease, cerebrovascular disease, or PVD) were significantly associated with exposure to IPs.

\section{Discussion}

The objective of this study was to investigate the prevalence of potential antithrombotic IP in hospitalized elderly patients by using the updated STOPP/START criteria version 2 . In recent years, several international studies have examined PIM use in different populations and settings, using STOPP/ START or Beers criteria. ${ }^{11-15,32-37}$ Our study is the first to use an African representative sample from Ethiopia regarding antithrombotic therapy to estimate the prevalence of PIMs, using the 2015 updated STOPP/START criteria. The updated 2015 STOPP/START criteria continue to highlight PIMs and PPOs in older adults using different classes of medications. During our study, results of the application of the updated criteria had not yet been published for any setting.

Our findings revealed a total number of 70 potential IPs in the GUH elderly patients fulfilling inclusion criteria. PIMs identified by STOPP were 51.4\%, while PPOs accounted for $48.6 \%$ in a population of 156 patients. Most of the PIMs detected with antithrombotic medication involved the use of platelet aggregation inhibitors (27.8\%) coadministered with vitamin $\mathrm{K}$ antagonists, direct TIs, or factor Xa inhibitors in patients with chronic AF. Except in the case of mechanical heart valve, studies do not recommend the use of aspirin along with anticoagulant in patients with $\mathrm{AF}$ as there are no added benefits and adequate data for clinical decision. ${ }^{38,39}$ The START tool was applied to assess the underprescription of clinically indicated antithrombotic medications and to identify specific contraindications in older patients. A total of 34 (48.6\%) PPOs were identified in 156 patients. Gallagher et $\mathrm{al}^{11}$ showed that the prevalence of PPOs using START criteria was higher in hospitalized elderly patients 
Table 4 Relationship between predictive variables and inappropriate prescribing exposure at Gondar University Hospital, Gondar, Ethiopia, between May I, 2013 and April 30, 2015

\begin{tabular}{|c|c|c|c|c|c|}
\hline \multirow[t]{2}{*}{ Variables } & \multicolumn{2}{|c|}{ IP per patient } & \multicolumn{2}{|l|}{ OR $(95 \% \mathrm{CI})$} & \multirow[t]{2}{*}{$P$-value } \\
\hline & Absent & Present & COR & AOR & \\
\hline \multicolumn{6}{|l|}{ Age } \\
\hline$\geq 85$ & 9 & 4 & 1 & 1 & - \\
\hline $65-74$ & 59 & 33 & $0.795(0.23-2.78)$ & $0.50(0.12,2.49)$ & 0.397 \\
\hline $75-84$ & 30 & 21 & $0.64(0.17-2.34)$ & $0.35(0.08-1.78)$ & 0.204 \\
\hline \multicolumn{6}{|l|}{ Sex } \\
\hline Female & 60 & 39 & 1 & 1 & - \\
\hline Male & 38 & 19 & $0.769(0.39-1.52)$ & $0.83(0.35,1.97)$ & 0.671 \\
\hline Days of hospital stay (mean) & 14.2 & 14.69 & $0.99(0.97-1.027)$ & $1.02(0.97,1.06)$ & $0.45 I$ \\
\hline Reason of admission & & & & & 0.33 \\
\hline Other & 6 & 5 & 1 & I & - \\
\hline $\mathrm{CHF}$ & 19 & 22 & $0.72(0.19-2.74)$ & I.7I $(0.30,9.66)$ & 0.545 \\
\hline VTE & 8 & I & $6.67(0.6 \mathrm{I}-73.03)$ & $29.87(1.26,708.6)^{*}$ & 0.035 \\
\hline Stroke & 43 & 16 & $2.24(0.59-8.37)$ & $7.74(1.27,47.29)^{*}$ & 0.027 \\
\hline $\mathrm{AF}$ & 5 & 10 & $0.42(0.08-2.06)$ & $1.55(0.18,13.09)$ & 0.687 \\
\hline ACS & 15 & 4 & $3.13(0.618-15.79)$ & $13.48(1.41,129.13)^{*}$ & 0.024 \\
\hline PVD & 2 & 0 & $134(0.00-N A)$ & $425(0.00-N A)$ & 0.999 \\
\hline Number of medications prescribed (mean) & 4.4 & 5.45 & $0.78(0.64,0.934)^{*}$ & $0.85(0.65, \mathrm{I} . \mathrm{II})$ & 0.22 \\
\hline Charlson comorbidity index (mean) & 2.02 & 2.34 & $0.76(0.55,1.03)$ & $0.60(0.39,0.945)^{*}$ & 0.027 \\
\hline \multicolumn{6}{|l|}{ Past history of PUD } \\
\hline No & 87 & 50 & 1 & I & - \\
\hline Yes & II & 8 & $0.79(0.298,2.095)$ & $1.55(0.42,5.72)$ & 0.51 \\
\hline \multicolumn{6}{|l|}{ History of recent bleeding } \\
\hline No & 91 & 54 & 1 & I & - \\
\hline Yes & 7 & 4 & $\mathrm{I} .04(0.29-3.7 \mathrm{I})$ & $2.71(0.48,15.52)$ & 0.26 \\
\hline \multicolumn{6}{|c|}{ History of coronary disease, cerebrovascular disease, or PVD } \\
\hline No & 64 & 29 & I & 1 & - \\
\hline Yes & 34 & 29 & $0.53(0.27-1.03)$ & $0.49(0.18,1.36)$ & 0.173 \\
\hline Types of antithrombotic therapy & & & & & 0.001 \\
\hline Both & 21 & 17 & 1 & 1 & - \\
\hline No therapy & 4 & 12 & $3.80(1.02-14.21)$ & $0.34(0.05,2.46)$ & 0.283 \\
\hline Anticoagulant only & 19 & 15 & I I. $57(3.23-4 \mid .42)^{*}$ & $1.26(0.304,5.22)$ & 0.750 \\
\hline Antiplatelet only & 54 & 14 & $3.71(1.01-13.59)^{* *}$ & $6.23(1.90,20.37)^{* *}$ & 0.002 \\
\hline
\end{tabular}

Notes: $* P<0.05, * * P<0.01$. “"” indicates reference variable. Data in bold indicates statistical significance $(P<0.05)$.

Abbreviations: ACS, acute coronary syndrome; AF, atrial fibrillation; $\mathrm{AOR}$, adjusted odds ratio; $\mathrm{CHF}$, congestive heart failure; $\mathrm{Cl}$, confidence interval; $\mathrm{COR}$, crude odds ratio; IP, inappropriate prescriptions; OR, odds ratio; PAD, peripheral arterial disease; PPI, proton pump inhibitor; PVD, peripheral vascular disease; PUD, peptic ulcer disease; VTE, venous thromboembolism; NA, not applicable.

(58\%-66\%) than in community-dwelling older adults (22\%). Compared with the study by Gallagher et al, ${ }^{11}$ PPOs were less prevalent in our settings due to the focus on elderly patients pertaining to antithrombotics therapy. In our study, 19/34 (56\%) PPOs were due to the underprescription of antiplatelet therapy for patients with a documented history of coronary disease, cerebrovascular disease, or PVD. Several experts and clinical guidelines have emphasized the benefit of adding antiplatelet drugs for the prevention of primary and secondary coronary events ${ }^{40-43}$ and thrombosis in elderly patients..$^{44,45}$ In this study, $41.2 \%$ of the PPOs were related to omission of vitamin $\mathrm{K}$ antagonists or direct TIs or factor Xa inhibitors for the AF patients. The omission of these drugs may increase the risk of stroke in elderly patients with AF. Several studies and international guidelines have prioritized the benefits of novel oral anticoagulants, vitamin K antagonists (warfarin), and other antithrombotics to prevent stroke in patients with nonvalvular AF. ${ }^{46-49}$

The prevalence of IP was higher in elderly patients with AF (66.6\%), followed by CHF (53.6\%) and stroke (27.1\%). A study conducted to assess the appropriateness of prescription in hospitalized elderly patients identified only $41 \%$ (41/99) patients with AF to have received appropriate stroke prophylaxis; contraindications to both warfarin and aspirin were documented in only $25 \%$ of AF patients. ${ }^{50} \mathrm{~A}$ recent review by Garber et al ${ }^{51}$ identified four recurrent safety factors 
while selecting antithrombotic agents for intermediate-risk to high-risk patients, which emphasized the need of appropriate drug use in stroke patients.

In our study, patients diagnosed with VTE, stroke, and ACS $(P<0.05)$ were less likely to be prescribed inappropriate antithrombotics according to STOPP/START criteria. The relationship between IP and antithrombotic agents has been extensively documented. ${ }^{3,4,52}$ Through a comprehensive literature review, Wilmer et $\mathrm{al}^{5}$ reported that antithrombotics and antidiabetics were highly associated with potential DRPs in clinical settings. In our study, a greater proportion of females received IP as compared with males, and a stronger association was noticed with antiplatelets alone $(P<0.05)$ according to STOPP/START criteria. Higher rates of IP in CHF (53.6\%) and AF (66.7\%) may therefore result in more frequent prescription of antithrombotic medication as compared with other hospitalization causes. Patients prescribed antiplatelets only were about six times less likely to have an IP than those receiving other groups of antithrombotics. Our findings highlight the importance of medication reviews to reduce the level of IP in hospitalized elderly populations.

This study has strengths. It has provided substantial findings regarding IP of antithrombotic drugs in elderly patients, particularly in developing countries such as Ethiopia as it is the first study in this area. Moreover, the updated STOPP/START version 2 was used. However, the results of our study should be interpreted with caution due to some limitations. We did not assess the incidence of adverse drug events, which may actually occur due to IP of antithrombotic therapy as the study design is a retrospective cross-sectional study. This study may suffer from generalizability as the study reviewed 156 patients' medical records obtained during admission day between May 1, 2013 and April 30, 2015, and was a single-center study done at GUH in Gondar city, Northwest Ethiopia.

\section{Conclusion}

We were able to uncover the substantial number of hospitalized older patients on antithrombotics in GUH that were exposed to IPs. IPs were found to be less common in elderly patients primarily admitted due to VTE, stroke, and ACS, and those elderly patients prescribed with only antiplatelet. Patients with higher CCI were, however, associated with increased IPs exposure. Therefore, our study may warrant further research to reduce high-risk prescription of antithrombotics in the elderly. Future studies should focus on assessing the impact of IPs on the patient discharge outcome and conducting interventional studies to identify IP of antithrombotic medications, thereby reducing adverse drug events.

\section{Acknowledgment}

The authors would like to thank Prof Shiri Diskin, Israel for editing the manuscript.

\section{Disclosure}

The authors report no conflicts of interest in this work.

\section{References}

1. Alquwaizani M, Buckley L, Adams C, Fanikos J. Anticoagulants: a review of the pharmacology, dosing, and complications. Curr Emerg Hosp Med Rep. 2013;1(2):83-97.

2. Desmaele S, De Wulf I, Dupont AG, Steurbaut S. Pharmacists' role in handling problems with prescriptions for antithrombotic medication in Belgian community pharmacies. Int J Clin Pharm. 2015;37(4):656-668.

3. Leendertse AJ, Egberts ACG, Stoker LJ, van den Bemt PM; HARM Study Group; Frequency of and risk factors for preventable medicationrelated hospital admissions in the Netherlands. Arch Intern Med. 2008; 168(17):1890-1896.

4. Ruiter R, Visser LE, Rodenburg EM, Trifiro G, Sticker BH. Adverse drug reaction-related hospitalizations in persons aged 55 years and over: a population-based study in the Netherlands. Drug Aging. 2012; 29(3):225-232.

5. Wilmer CM, Huisken VJB, Natsch S, Rennings AJM, van de Bernt BJF, Bis JM. Drug-related problems in a clinical setting: a literature review and cross-sectional study evaluating factors to identify patient at risk. Eur J Hosp Pharm. 2015;22(4):189-190.

6. James MW. Pharmacotherapy considerations in elderly adults. South Med J. 2012;105(8):437-445.

7. PCNE. Classification for drug related problems V6.2. [Internet] Zuidlaren, NL: Pharmaceutical Care Network Europe Foundation 2010 [cited 2015, 2015-12-02]; Available from: http://www.pcne.org/ upload/files/11_PCNE_classification_V6-2.pdf

8. Modig S, Holmdahl L, Bondesson A. Medication reviews in primary care in Sweden: importance of clinical pharmacists' recommendations on drug-related problems. Int J Clin Pharm. 2015;38(1):41-45.

9. Selcuk A, Sancar M, Okuyan B, Demirtunc R, Izzettin FV. The potential role of clinical pharmacists in elderly patients during hospital admission. Pharmazie. 2015;70(8):559-562.

10. Milos V, Rekman E, Bondesson A, et al. Improving the quality of pharmacotherapy in elderly primary care patients through medication reviews: a randomised controlled study. Drug Aging. 2013;30(4): 235-246.

11. Gallagher PF, O'Connor MN, O'Mahony D. Prevention of potentially inappropriate prescribing for elderly patients: a randomized controlled trial using STOPP/START criteria. Clin Pharmacol Ther. 2011; 89(6):845-854.

12. Gillespie U, Alassaad A, Hammarlund-Udenaes M, et al. Effectiveness of pharmacists' interventions on appropriateness of prescribing and evaluation of the instruments' (MAI, STOPP and STARTs') ability to predict hospitalization - analysis from a randomized controlled trial PLoS One. 2013;8(5):e62401.

13. Stafford AC, Alswayan MS, Tenni PC. Inappropriate prescribing in older residents of Australian care homes. J Clin Pharm Ther. 2011; 36(1):33-44.

14. Lau DT, Kasper JD, Potter DE, Lyles A, Bennett RG. Hospitalization and death associated with potentially inappropriate medication prescriptions among elderly nursing home residents. Arch Intern Med. 2005; 165(1):68-74.

15. Lund BC, Carnahan RM, Egge JA, Chrischilles EA, Kaboli PJ. Inappropriate prescribing predicts adverse drug events in older adults. Ann Pharmacother. 2010;44(6):957-963.

16. Beers MH, Ouslander JG, Rollingher I, Reuben DB, Brooks J, Beck JC Explicit criteria for determining inappropriate medication use in nursing home residents. Arch Intern Med. 1991;151(9):1825-1832. 
17. Fick DM, Cooper JW, Wade WE, Waller JL, Maclean JR, Beers MH. Updating the Beers criteria for potentially inappropriate medication use in older adults: results of a US consensus panel of experts. Arch Intern Med. 2003;163(22):2716-2724.

18. McLeod PJ, Huang AR, Tamblyn RM, Gayton DC. Defining inappropriate practices in prescribing for elderly people: a national consensus panel. CMAJ. 1997;156(3):385-391.

19. Naugler CT, Brymer C, Stolee P, Arcese ZA. Development and validation of an improving prescribing in the elderly tool. Can J Clin Pharmacol. 2000;7(2):103-107.

20. Cantrill JA, Sibbald B, Buetow S. Indicators of the appropriateness of long-term prescribing in general practice in the United Kingdom: consensus development, face and content validity, feasibility and reliability. Qual Health Care. 1998;7(3):130-135.

21. Zhan C, Sangl J, Bierman AS, et al. Potentially inappropriate medication use in the community-dwelling elderly: findings from the 1996 medical expenditure panel survey. JAMA. 2001;286(22):2823-2829.

22. Laroche ML, Charmes JP, Merle L. Potentially inappropriate medications in the elderly: a French consensus panel list. Eur J Clin Pharmacol. 2007;63(8):725-731.

23. Basger BJ, Chen TF, Moles RJ. Inappropriate medication use and prescribing indicators in elderly Australians: development of a prescribing indicators tool. Drugs Aging. 2008;25(9):777-793.

24. Rognstad S, Brekke M, Fetveit A, Spigset O, Wyller TB, Straand J. The Norwegian General Practice (NORGEP) criteria for assessing potentially inappropriate prescriptions to elderly patients: a modified Delphi study. Scand J Prim Health Care. 2009;27:153-159.

25. Holt S, Schmeidl S, Thurmann PA. Potentially inappropriate medications in the elderly: the PRISCUS List. Dtsch Arztebl Int. 2010;107(31-32): $543-551$.

26. Winit-Watjana W, Sakulrat $\mathrm{P}$, Kespichayawattana J. Criteria for highrisk medication use in Thai older patients. Arch Gerontol Geriatr. 2008; 47(1):35-51.

27. Rancourt C, Moisan J, Baillargeon L, Verreault R, Laurin D, Grégoire JP. Potentially inappropriate prescriptions for older patients in long-term care. BMC Geriatr. 2004;4:9.

28. O'Mahony D, O'Sullivan D, Byrne S, O'Connor MN, Ryan C, Gallagher P. STOPP/START criteria for potentially inappropriate prescribing in older people: version 2. Age Ageing. 2015;44(2):213-218.

29. O’Connor M, Gallagher P, O'Mahony D. Inappropriate prescribing: criteria, detection and prevention. Drugs Aging. 2012;29(6):437-452.

30. International Classification of Diseases (ICD). (n.d). Available from: http://www.who.int/classifications/icd/en/

31. Charlson ME, Pompei P, Ales KL, MacKenzie CR. A new method of classifying prognostic comorbidity in longitudinal studies: development and validation. J Chronic Dis. 1987;40(5):373-383.

32. Davidoff AJ, Miller EG, Sarpong EM, Yang E, Brandt N, Fick DM. Prevalence of potential inappropriate medication use in older adults using the 2012 Beers criteria. J Am Geriatr Soc. 2015;63:486-500.

33. Campanelli CM. American Geriatrics Society updated Beers Criteria for potentially inappropriate medication use in older adults. $J$ Am Geriatr Soc. 2012;60:616-631.

34. Koyama A, Steinman M, Ensrud K, Hillier TA, Yaffe K. Long-term cognitive and functional effects of potentially inappropriate medications in older women. J Gerontol A Biol Sci Med Sci. 2014;69(4):423-429.

35. Chang CB, Chan DC. Comparison of published explicit criteria for potentially inappropriate medications in older adults. Drugs Aging. 2010;27(12):947-957.

36. Bao Y, Shao H, Bishop TF, Schackman BR, Bruce ML. Inappropriate medication in a national sample of US elderly patients receiving home health care. J Gen Intern Med. 2012;27(3):304-310.
37. Mattison ML, Afonso KA, Ngo LH, Mukamal KJ. Preventing potentially inappropriate medication use in hospitalized older patients with a computerized provider order entry warning system. Arch Intern Med. 2010; 170(15):1331-1336.

38. Flaker GC, Gruber M, Connolly SJ. Risks and benefits of combining aspirin with anticoagulant therapy in patients with atrial fibrillation: an exploratory analysis of stroke prevention using an oral thrombin inhibitor in atrial fibrillation (SPORTIF) trials. Am Heart J. 2006;152(5):967-973.

39. Larson RJ, Fisher ES. Should aspirin be continued in patients started on warfarin? J Gen Intern Med. 2004;19(8):879-886.

40. Fleg JL, Aronow WS, Frishman WH. Cardiovascular drug therapy in the elderly: benefits and challenges. Nat Rev Cardiol. 2011;8(1):13-28.

41. Andrawes WF, Bussy C, Belmin J. Prevention of cardiovascular events in elderly people. Drug Aging. 2005;22(10):859-876.

42. Flega JL, Wengerb NK. Prevention of cardiovascular disease in older adults. In: Lanzer P, editor. PanVascular Medicine. Berlin/Heidelberg: Springer, 2014:1-28.

43. Zuckerman IH, Yin X, Rattinger GB, et al. Effect of exposure to evidence-based pharmacotherapy on outcomes after acute myocardial infarction in older adults. J Am Geriatr Soc. 2012;60(10):1854-1861.

44. Alonso-Coello P, Bellmunt S, McGorrian C, et al. American College of Chest Physicians. Antithrombotic therapy in peripheral artery disease: Antithrombotic Therapy and Prevention of Thrombosis, 9th ed: American College of Chest Physicians Evidence-Based Clinical Practice Guidelines. Chest. 2012;141(2 Suppl):e669S-e690S.

45. Vandvik PO, Lincoff AM, Gore JM, et al; American College of Chest Physicians; Primary and secondary prevention of cardiovascular disease: Antithrombotic Therapy and Prevention of Thrombosis, 9th ed: American College of Chest Physicians Evidence-Based Clinical Practice Guidelines. Chest. 2012;141(2 Suppl):e637S-e668S. Erratum in: Chest. 2012;141(4):1129.

46. Hughes M, Lip GY; Guideline Development Group, National Clinical Guideline for Management of Atrial Fibrillation in Primary and Secondary Care, National Institute for Health and Clinical Excellence; Stroke and thromboembolism in atrial fibrillation: a systematic review of stroke risk factors, risk stratification schema and cost effectiveness data. Thromb Haemost. 2008;99(2):295-304.

47. Dentali F, Riva N, Crowther M, Turpie AG, Lip GY, Ageno W. Efficacy and safety of the novel oral anticoagulants in atrial fibrillation: a systematic review and meta-analysis of the literature. Circulation. 2012; 126(20):2381-2391.

48. Hart RG, Pearce LA, Aguilar MI. Metaanalysis: antithrombotic therapy to prevent stroke in patients who have non-valvular atrial fibrillation. Ann Intern Med. 2007;146(12):857-867.

49. Shehab A, Elnour AA, Bhagavathula AS, et al. Novel oral anticoagulants and the 73rd anniversary of historical warfarin. J Saudi Heart Assoc. 2016;28(1):31-45.

50. Oborne AC, Hooper R, Swift CG, Jackson SH. Explicit, evidence-based criteria to assess the quality of prescribing to elderly nursing home residents. Age Ageing. 2003;32(1):102-108.

51. Garber JL, Willenborg KL, Rose AE. Analysis of anticoagulant prescribing in non-valvular atrial fibrillation and development of clinical tool for guiding anticoagulant selection. J Throm Thrombolysis. 2015; 40(2):248-254

52. Olivier P, Bertrand L, Tubery M, Lauque D, Montastruc JL, LapeyreMestre M. Hospitalizations because of adverse drug reactions in elderly patients admitted through the emergency department. A prospective survey. Drugs Aging. 2009;26(6):475-482. 
Clinical Interventions in Aging

\section{Publish your work in this journal}

Clinical Interventions in Aging is an international, peer-reviewed journal focusing on evidence-based reports on the value or lack thereof of treatments intended to prevent or delay the onset of maladaptive correlates of aging in human beings. This journal is indexed on PubMed Central, MedLine,

CAS, Scopus and the Elsevier Bibliographic databases. The manuscript management system is completely online and includes a very quick and fair peer-review system, which is all easy to use. Visit http://www.dovepress. $\mathrm{com} /$ testimonials.php to read real quotes from published authors.

Submit your manuscript here: http://www.dovepress.com/clinical-interventions-in-aging-journal 